\section{BMJ Open Respiratory Research}

\title{
Asthma control is associated with economic outcomes, work productivity and health-related quality of life in patients with asthma
}

\author{
Lulu K Lee, ${ }^{1}$ Karthik Ramakrishnan, ${ }^{2}$ Guilherme Safioti, ${ }^{3}$ Rinat Ariely, ${ }^{2}$ \\ Michael Schatz ${ }^{4}$
}

To cite: Lee LK, Ramakrishnan K, Safioti G, et al. Asthma control is associated with economic outcomes, work productivity and health-related quality of life in patients with asthma. BMJ Open Resp Res 2020;7:e000534. doi:10.1136/ bmjresp-2019-000534

- Additional material is published online only. To view please visit the journal online (http://dx.doi.org/10.1136/ bmjresp-2019-000534).

Received 19 November 2019 Revised 3 February 2020 Accepted 13 February 2020

Check for updates

(C) Author(s) (or their employer(s)) 2020. Re-use permitted under CC BY-NC. No commercial re-use. See rights and permissions. Published by BMJ.

${ }^{1}$ Health Outcomes Real-World Evidence, Kantar Health, San Mateo, California, USA

${ }^{2}$ Global Health Economics \& Outcomes Research, Teva Branded Pharmaceutical Products R\&D, Inc, West Chester, Pennsylvania, USA ${ }^{3}$ Connected Respiratory, Teva Pharmaceutical Industries, Amsterdam, Netherlands ${ }^{4}$ Department of Allergy, Kaiser Permanente Southern California Region, San Diego and Pasadena, California, USA

Correspondence to

Lulu K Lee;

lulu.lee@kantar.com

\section{ABSTRACT}

Background The objective of this analysis was to examine the association between asthma control (based on Asthma Control Test (ACT) responses) and healthcare resource utilisation (HRU), work productivity and healthrelated quality of life (HRQoL) among a nationwide sample of US adults with a self-reported diagnosis of asthma and without comorbid chronic obstructive pulmonary disease. Methods Data were obtained from the 2015 and 2016 self-administered, internet-based National Health and Wellness Surveys. Patients were grouped by ACT score ( $\leq 15$ : poorly controlled; 16-19: partly controlled; 20-25: well-controlled asthma). Study outcomes included HRU (patient-reported healthcare provider visits, emergency department visits and hospitalisations during the previous 6 months); work productivity, measured using the Work Productivity and Activity Impairment-General Health Scale; HRU-associated costs and work productivity loss and HRQoL, measured using EuroQoL-5 Dimensions- 5 Levels (EQ-5D-5L) and the Short Form Health Survey-36V.2 (SF-36V.2). Incremental differences in outcomes between groups were assessed using generalised linear models adjusted for covariates.

Results 0 7820 eligible adults, $17.4 \%$ had poorly controlled, $20.1 \%$ partly controlled and $62.5 \%$ wellcontrolled asthma. Well-controlled asthma was associated with significantly lower HRU $(p<0.001)$ and lower mean direct costs ( $\$ 6012$ vs $\$ 8554$ and $\$ 15262$, respectively; $\mathrm{p}<0.001$ ); well-controlled asthma was also associated with significantly lower mean scores for work absenteeism, work presenteeism, overall work impairment and activity impairment (all $p<0.001$ ), and lower mean indirect costs (\$6353 vs $\$ 10448$ and $\$ 14764$, respectively; $\mathrm{p}<0.001)$. Clinically meaningful differences favouring wellcontrolled asthma were seen for all HRQoL measures, with statistically significantly higher adjusted mean EQ-5D-5L index and SF-6D Health Utilities Index scores (derived from SF-36V.2) for patients with well-controlled asthma compared with partly controlled or poorly controlled asthma $(p<0.001)$.

Conclusions The study demonstrates a clear relationship between asthma control and its impact on HRU, costs, work productivity and HRQOL. This will allow for better identification and management of patients with poorly controlled asthma.

\section{Key messages}

This study used Asthma Control Test questionnaire responses to determine the relationship between asthma control and the costs of health resource utilisation, work productivity and health-related quality of life (HRQoL) in adult patients with asthma

- This large US study demonstrates a clear relationship between asthma control and its impact on healthcare resource utilisation, costs, work productivity and HRQoL, which will allow for better identification and management of patients with poorly controlled asthma.

- This study provides a contemporary picture of $\mathrm{HRQOL}$ and health resource utilisation across the spectrum of patients with asthma and reinforces findings from other studies showing that the Asthma Control Test questionnaire can detect meaningful differences in asthma control in the population.

\section{INTRODUCTION}

Asthma is one of the most common chronic diseases, affecting approximately 334 million people worldwide. ${ }^{1}$ In the USA, national data from the 2016 National Health Interview Survey estimated that more than 26 million people $\left(8.3 \%\right.$ of adults) suffer from asthma. ${ }^{2}$ Of these adults with asthma, nearly half (44.9\%) reported experiencing at least one asthma attack during the last year. ${ }^{2}$ Asthma represents a considerable and growing burden to the US healthcare system, with treatment (including emergency care and hospitalisations) translating to an estimated total annual cost of approximately $\$ 82$ billion. ${ }^{3}$

The Global Initiative for Asthma recommends that assessment of asthma should include the determination of asthma control (both symptom control and future risk of adverse outcomes). ${ }^{4}$ Despite these recommended goals and the availability of effective therapies, several studies have shown that asthma is frequently poorly controlled. ${ }^{4-7}$ 
Those with poorly controlled asthma, compared with those without asthma, have a 4.6-fold greater frequency of hospitalisations, up to 1.8-fold more emergency department (ED) visits and lower work productivity (with a greater likelihood of unemployment, activity limitations and absenteeism from work) ${ }^{8}$ Indeed, the disproportionately high costs associated with poorly controlled asthma have important public health implications. In addition, poorly controlled asthma is associated with impaired patient health-related quality of life (HRQoL). ${ }^{9}$ Therefore, achieving asthma control is a main concern for physicians and providers who care for patients with asthma. To this end, additional studies that evaluate asthma control and its effects in contemporary asthma populations are required to better identify and manage patients with poorly controlled asthma.

The Asthma Control Test (ACT) questionnaire is a selfadministered, validated tool for identifying patients with poorly controlled asthma. ${ }^{10}$ While the ACT was initially tested and validated on physician visits, with subsequent use in postal and telephone surveys, recent internet surveys have provided valuable, up-to-date data on the level of asthma control in the population, and the associated patient and healthcare burden of poor asthma control. ${ }^{11-13}$

The objective of the present analysis was to examine the association between asthma control and health and economic outcomes among patients with asthma. ACT questionnaire responses collated by the internet-based self-administered US National Health and Wellness Survey (NHWS) from 2015 and 2016 were used to determine the relationship ACT and the costs of care (healthcare resource utilisation (HRU)), work productivity and HRQoL in adult patients with asthma. NHWS provides an opportunity to analyse real-world data outside of the highly controlled clinical trial setting for information on clinical characteristics, treatment patterns and patientreported outcomes that might not otherwise be available in administrative data such as insurance claims.

\section{METHODS}

\section{Study design and participants}

This was a retrospective, non-interventional, crosssectional data analysis based on a representative sample of US adults aged $\geq 18$ years with a self-reported physician diagnosis of asthma and without self-reported comorbid chronic obstructive pulmonary disease (COPD). Data were obtained from the 2015 and 2016 NHWS. ${ }^{14}$ The survey comprised a base component, answered by all respondents (which assessed demographics, diseases experienced and diagnosed and health outcomes) and various disease-specific modules (such as an asthma module), which were completed by eligible patients selected randomly based on a priori assigned probability.

All data were collected from patients at a single timepoint. The results from the 2015 and 2016 surveys were collated to increase the sample size for analysis. If a respondent had participated in consecutive years of the survey, only the most recent 2016 survey data were retained and included in the analysis.

\section{Study measures and outcomes}

Asthma control was determined based on patients' responses to the ACT questionnaire. ${ }^{10}$ The ACT consists of five items, based on the 4-week recall of symptoms and daily functioning. It is designed to assess the frequency of shortness of breath and general asthma symptoms, use of rescue medications, the effect of asthma on daily functioning and overall self-assessment of asthma control. Patients were grouped according to their level of asthma control as follows: ACT score $\leq 15$, poorly controlled asthma; ACT score 16-19, partly controlled asthma; ACT score 20-25, well-controlled asthma. ${ }^{10}$

Covariates considered in the analysis included age, sex, race/ethnicity, education, income, insurance type, body mass index (BMI), smoking status, exercise, years diagnosed with asthma and comorbidity burden (measured by Charlson Comorbidity Index (CCI) scores, where a higher total CCI index score indicates a greater comorbidity burden). ${ }^{15}$

Morisky Medication Adherence Scale (MMAS-8) (the use of the @MMAS- 8 is protected by US copyright laws. Permission for use is required. A license agreement is available from Donald E. Morisky, MMAS Research (MORISKY) 16636 159th Place SE, Renton WA 98058), a validated eight-item scale, was used to assess overall patient non-adherence or adherence to asthma medications (inhaler use). ${ }^{16}$ Scores indicate high adherence (8), medium adherence $(6$ to $<8)$ or low adherence $(<6)$.

HRU was defined by the number of healthcare provider visits, ED visits and hospitalisations in the previous 6 months. Direct healthcare costs were derived from patient-reported HRU. For each respondent, the number of each type of visit was multiplied by two to project the annual number of visits, which was then multiplied by the average cost for each type of visit, taken from the 2014 Medical Expenditure Panel Survey. ${ }^{17}$ The figures obtained for each type of visit were summed to derive a total direct cost value for each respondent.

Work-related outcomes for each part-time or fulltime employed respondent were derived from the Work Productivity and Activity Impairment-General Health Scale (WPAI-GH V.2.0), a six-item validated instrument, consisting of four metrics: absenteeism (percentage of work time missed due to one's health in the past 7 days), presenteeism (percentage of impairment experienced while at work in the past 7 days due to health), overall work productivity loss (an overall impairment estimate that is a combination of absenteeism and presenteeism) and activity impairment (the percentage of impairment in daily activities due to health in the past 7 days). Higher scores indicate higher impairment. ${ }^{18} 19$ Total hours lost due to overall work impairment could be determined by multiplying overall work impairment, expressed as 
a percentage, by 40 (the estimated number of working hours).

Median weekly wages by age and sex were obtained from the 2014 Bureau of Labor Statistics. From these weekly wages, we estimated an hourly wage by dividing the figures by 40 hours. Next, for each respondent, the number of hours missed due to absenteeism and the number of hours missed due to presenteeism were multiplied by their associated hourly wage, based on age and sex. These figures, which represent societal lost earnings per employee per week for absenteeism and presenteeism, respectively, were then annualised by multiplying by 50 work weeks in a year. The annual costs for absenteeism and presenteeism were combined to form total indirect costs.

HRQoL was determined using the most recent version of the EQ-5D instrument (EuroQoL-5 Dimensions-5 Levels (EQ-5D-5L) $)^{20}$ and the Short Form Health Survey-36V.2 (SF-36V.2). ${ }^{21}$ The EQ-5D-5L is a widely used survey instrument, which measures quality of life in five dimensions: mobility, self-care, usual activities, pain/discomfort and anxiety/depression. Among each domain, health is measured using five levels of severity: no problems, slight problems, moderate problems, severe problems and unable to perform/extreme problems. Scores on the EQ-5D range from less than 0 (where 0 is equivalent to dead and negative values represent worse than dead) to 1 (full health), with higher scores indicating better generic health status. The minimally important difference (MID) for EQ-5D-5L is considered to be approximately 0.07 points. ${ }^{22}$

The SF-36V.2 comprises eight health domains as well as two component summary scores: the mental component summary (MCS) and physical component summary (PCS). Items from the SF-36V.2 were used to derive a preference-based health utility index, the SF-6D health utilities index, to be used for health economic assessment. Using the SF-6D classification system, the response pattern of the SF-36V.2 items was converted to a health utility score varying from 0 (a health state equivalent to death) to 1 (a health state equivalent to perfect health). Differences in five points on the norm-based domain scores, three points on the norm-based component summary scores and 0.041 points on health utilities are considered to represent clinically meaningful differences. $^{21} 22$

\section{Statistical methods}

A bivariate analysis was used to measure differences among patients with different ACT scores with respect to demographics, health characteristics and asthma characteristics (including years diagnosed with asthma and treatments). Chi-square tests and one-way analysis of variance were used to test differences in categorical and continuous outcomes, respectively.

To determine whether study outcomes (EQ-5D-5L, SF-36V.2 metrics, WPAI, HRU, costs) differed by levels of asthma control, a multivariable analysis was carried out using a series of generalised linear models, adjusting for covariates. The covariates included were significantly different between groups at baseline, they included age, sex, race, education, income, insurance type, BMI, smoking status, exercise, years diagnosed with asthma, as well as comorbidities (CCI). It was determined that specifying a negative binomial distribution with a loglink function would provide the best fit to the outcomes data. Corrections to the standard errors were applied to correct for underdispersion or overdispersion. Regression estimates, rate ratios (RR; where appropriate), adjusted means, 95\% CIs and p-values were reported for each predictor. For all statistical analyses, p-values of $<0.05$ were considered statistically significant.

\section{Patient and public involvement}

This research was done without patient involvement. Patients were not invited to comment on the study design and were not consulted to develop patient relevant outcomes or interpret the results. Patients were not invited to contribute to the writing or editing of this document for readability or accuracy.

\section{RESULTS}

This study included respondents from the 2015 and 2016 US NHWS (total combined $n=195203$ ). Of the 168241 non-duplicate respondents, 16705 answered that they had experienced asthma in the previous 12 months and were selected into the asthma module of the survey; of these, 8650 patients had a self-reported physician diagnosis of asthma, of which 7820 had asthma without comorbid COPD and were eligible for this analysis (online supplementary figure $\mathrm{S} 1$ ).

Of the 7820 eligible patients, 1360 (17.4\%) had poorly controlled asthma (ACT score $\leq 15) ; 1572$ (20.1\%) had partly controlled asthma (ACT score 16-19) and 4888 (62.5\%) had well-controlled asthma (ACT score 20-25).

\section{Baseline characteristics according to ACT group}

Overall, higher levels of asthma control (ACT: 20-25 vs $16-19$ and $\leq 15$; all $p<0.001$ ) were significantly associated with being non-Hispanic white, having a college degree or higher, greater annual household income, having private insurance, exercising more than once in the previous month, not being obese and not smoking (table 1). Race, education, income, insurance type, exercise, BMI and smoking status were all covariates adjusted for in the multivariable analysis.

In terms of the burden of comorbidities, a higher proportion of patients with poorly controlled asthma had a higher score on the adjusted CCI than patients with partly controlled or well-controlled asthma (table 1). Compared with those with poorly controlled asthma, the following comorbidities were less prevalent in patients with well-controlled asthma: chronic bronchitis, 
Table 1 Patient demographics and baseline characteristics by ACT groups

\begin{tabular}{|c|c|c|c|c|c|c|c|}
\hline & \multicolumn{2}{|c|}{$\begin{array}{l}\text { ACT score } \leq 15 \\
(n=1360)\end{array}$} & \multicolumn{2}{|c|}{$\begin{array}{l}\text { ACT score } 16-19 \\
(n=1572)\end{array}$} & \multicolumn{2}{|c|}{$\begin{array}{l}\text { ACT score } 20-25 \\
(n=4888)\end{array}$} & \multirow[b]{2}{*}{ P-value } \\
\hline & $\% /$ Mean & N/SD & $\% /$ Mean & N/SD & $\% /$ Mean & N/SD & \\
\hline Sex, female, \% (n) & 66.4 & 903 & 68.3 & 1074 & 67.5 & 3299 & 0.540 \\
\hline \multicolumn{8}{|l|}{ Race/ethnicity } \\
\hline Hispanic & 18.2 & 248 & 15.3 & 241 & 12.9 & 629 & \multirow{2}{*}{$<0.001$} \\
\hline Other ethnicity & 15.7 & 213 & 15.3 & 241 & 15.9 & 779 & \\
\hline \multicolumn{8}{|l|}{ Married/living with partner } \\
\hline $\begin{array}{l}\text { Single/divorced/separated/ } \\
\text { widowed/decline to answer }\end{array}$ & 46.9 & 638 & 49.8 & 783 & 48.2 & 2354 & 0.284 \\
\hline$<4$ year college degree & 68.8 & 935 & 69.3 & 1090 & 57.9 & 2830 & \multirow[t]{3}{*}{$<0.001$} \\
\hline 4 year college degree or higher & 31.3 & 425 & 30.4 & 478 & 41.8 & 2045 & \\
\hline Declined to answer & 0.0 & 0 & 0.3 & 4 & 0.3 & 13 & \\
\hline \multicolumn{8}{|l|}{ Annual household income } \\
\hline$<\$ 25 \mathrm{k}$ & 30.7 & 417 & 27.4 & 431 & 19.4 & 949 & \multirow[t]{5}{*}{$<0.001$} \\
\hline$\$ 25 \mathrm{k}$ to $\$ 50 \mathrm{k}$ & 28.3 & 385 & 26.5 & 417 & 24.7 & 1206 & \\
\hline$\$ 50 \mathrm{k}$ to $\$ 75 \mathrm{k}$ & 14.6 & 199 & 17.3 & 272 & 19.8 & 966 & \\
\hline$\$ 75 \mathrm{k}$ or more & 22.1 & 301 & 22.5 & 354 & 29.3 & 1431 & \\
\hline Declined to answer & 4.3 & 58 & 6.2 & 98 & 6.9 & 336 & \\
\hline $\begin{array}{l}\text { Civilian Health and Medical } \\
\text { Program of the Department of } \\
\text { Veterans Affairs (CHAMPVA) }\end{array}$ & 1.2 & 15 & 0.9 & 13 & 0.9 & 42 & \multirow{3}{*}{$<0.001$} \\
\hline TRICARE & 1.8 & 22 & 1.7 & 24 & 2.0 & 90 & \\
\hline Other/unsure & $5.6^{*}$ & 68 & $5.2 \dagger$ & 74 & $5.7 \ddagger$ & 255 & \\
\hline \multicolumn{8}{|l|}{ BMI category } \\
\hline $\begin{array}{l}\text { Underweight } \\
\left(\mathrm{BMl}<18.5 \mathrm{~kg} / \mathrm{m}^{2}\right)\end{array}$ & 4.6 & 62 & 2.5 & 40 & 2.5 & 124 & \multirow[t]{5}{*}{$<0.001$} \\
\hline $\begin{array}{l}\text { Normal weight } \\
\left(\text { BMI } 18.5-24.9 \mathrm{~kg} / \mathrm{m}^{2}\right)\end{array}$ & 23.2 & 315 & 26.9 & 423 & 28.7 & 1401 & \\
\hline $\begin{array}{l}\text { Overweight } \\
\left(\text { BMI } 25.0-29.9 \mathrm{~kg} / \mathrm{m}^{2}\right)\end{array}$ & 23.4 & 318 & 24.3 & 382 & 28.7 & 1405 & \\
\hline Obese $\left(\mathrm{BMl}>30.0 \mathrm{~kg} / \mathrm{m}^{2}\right)$ & 45.7 & 622 & 42.2 & 663 & 36.6 & 1791 & \\
\hline Unknown & 3.2 & 43 & 4.1 & 64 & 3.4 & 167 & \\
\hline \multicolumn{8}{|l|}{ Smoking status } \\
\hline Current smoker & 27.1 & 369 & 22.3 & 351 & 11.0 & 540 & \multirow[t]{3}{*}{$<0.001$} \\
\hline Former smoker & 22.4 & 305 & 26.5 & 417 & 26.3 & 1287 & \\
\hline Never smoker & 50.4 & 686 & 51.1 & 804 & 62.6 & 3061 & \\
\hline Drink alcohol & & & & & & & \\
\hline
\end{tabular}


Table 1 Continued

\begin{tabular}{|c|c|c|c|c|c|c|c|}
\hline & \multicolumn{2}{|c|}{$\begin{array}{l}\text { ACT score } \leq 15 \\
(n=1360)\end{array}$} & \multicolumn{2}{|c|}{$\begin{array}{l}\text { ACT score } 16-19 \\
(n=1572)\end{array}$} & \multicolumn{2}{|c|}{$\begin{array}{l}\text { ACT score } 20-25 \\
(n=4888)\end{array}$} & \multirow[b]{2}{*}{ P-value } \\
\hline & $\% /$ Mean & N/SD & $\% /$ Mean & N/SD & $\% /$ Mean & N/SD & \\
\hline No & 36.6 & 498 & 35.9 & 565 & 35.1 & 1714 & 0.528 \\
\hline Yes & 63.4 & 862 & 64.1 & 1007 & 64.19 & 3174 & \\
\hline $\begin{array}{l}\text { Exercise } 20+\text { min } \\
1+\text { times in past month }\end{array}$ & 60.9 & 828 & 59.5 & 936 & 64.7 & 3162 & $<0.001$ \\
\hline $\mathrm{CCl}$ & 0.94 & 1.57 & 0.69 & 1.22 & 0.50 & 1.04 & $<0.001$ \\
\hline \multicolumn{8}{|l|}{$\mathrm{CCl}$ categories } \\
\hline $\mathrm{CCl} 0$ & 53.7 & 730 & 63.6 & 1000 & 71.7 & 3505 & $<0.001$ \\
\hline $\mathrm{CCl} 1$ & 24.9 & 339 & 19.5 & 307 & 16.5 & 806 & \\
\hline $\mathrm{CCl} 2$ & 11.3 & 154 & 9.4 & 147 & 6.8 & 332 & \\
\hline $\mathrm{CCl} 3+$ & 10.1 & 137 & 7.5 & 118 & 5.0 & 245 & \\
\hline \multicolumn{8}{|c|}{ Asthma treatment at baseline } \\
\hline \multicolumn{8}{|l|}{ ICS } \\
\hline No & 74.1 & 814 & 77.6 & 916 & 80.8 & 2481 & $<0.001$ \\
\hline Yes & 25.9 & 285 & 22.4 & 265 & 19.2 & 588 & \\
\hline \multicolumn{8}{|l|}{ LABA } \\
\hline No & 98.0 & 1077 & 99.1 & 1170 & 99.0 & 3038 & 0.022 \\
\hline Yes & 2.0 & 22 & 0.9 & 11 & 1.0 & 31 & \\
\hline \multicolumn{8}{|l|}{ ICS/LABA combination } \\
\hline No & 60.6 & 666 & 64.0 & 756 & 70.7 & 2169 & $<0.001$ \\
\hline Yes & 39.4 & 433 & 36.0 & 425 & 29.3 & 900 & \\
\hline \multicolumn{8}{|l|}{ SABA } \\
\hline No & 19.6 & 215 & 19.2 & 227 & 24.2 & 743 & $<0.001$ \\
\hline Yes & 80.4 & 884 & 80.8 & 954 & 75.8 & 2326 & \\
\hline \multicolumn{8}{|l|}{ Leukotriene } \\
\hline No & 76.7 & 843 & 81.3 & 960 & 81.9 & 2514 & 0.001 \\
\hline Yes & 23.3 & 256 & 18.7 & 221 & 18.1 & 555 & \\
\hline \multicolumn{8}{|l|}{ Theophylline } \\
\hline No & 97.6 & 1073 & 99.2 & 1171 & 99.4 & 3051 & $<0.001$ \\
\hline Yes & 2.4 & 26 & 0.8 & 10 & 0.6 & 18 & \\
\hline \multicolumn{8}{|l|}{ Anti-lgE } \\
\hline No & 98.5 & 1082 & 99.2 & 1172 & 99.4 & 3052 & 0.007 \\
\hline Yes & 1.5 & 17 & 0.8 & 9 & 0.6 & 17 & \\
\hline
\end{tabular}

*\% excludes 155 patients with missing data.

$\dagger \%$ excludes 160 patients with missing data.

‡\% excludes 433 patients with missing data. P-value represents omnibus analysis of variance $p$-values.

$\mathrm{ACT}$, asthma control test; Anti-IgE, anti-immunoglobulin E; BMI, body mass index; CCI, Charlson Comorbidity Index; ICS, inhaled

corticosteroids; LABA, long-acting beta-agonists; SABA, short-acting beta-agonists; SD, standard deviation.

rheumatoid arthritis, gastric ulcers, skin ulcers/cellulitis, congestive heart failure, type 1 or type 2 diabetes or endorgan damage due to diabetes, hemiplegia, dementia, connective tissue disease, chronic liver disease, Hepatitis C, Hepatitis B, HIV and AIDS.

Higher ACT scores (ACT: $20-25$ vs $16-19$ and $\leq 15$ ) were significantly associated with lower reported levels of severe persistent asthma (when not using asthma medication), and fewer patients with well-controlled compared with partly controlled or poorly controlled asthma reported being on inhaled corticosteroids (ICS) plus long-acting beta-agonist (LABA) as maintenance therapy: $29.4 \%$ versus $36.0 \%$ and $39.4 \%$; $<<0.001$, receiving dose increases of their ICS and/or LABA treatment or requiring add-on therapy ( $14.7 \%$ vs $21.7 \%$ vs $30.3 \%$; $\mathrm{p}<0.001)$. More patients with well-controlled asthma versus partly controlled or poorly controlled asthma also reported replacing their existing asthma medication in the last year $(74.3 \%$ vs $66.3 \%$ and $57.5 \%$; $<<0.001$; table 1). A high proportion of patients with asthma in 

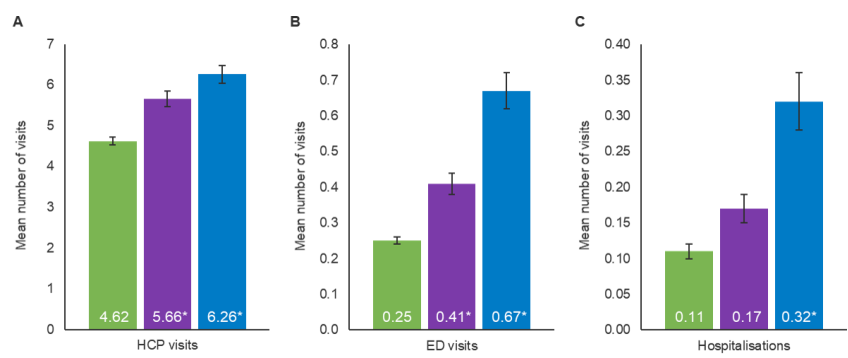

Figure 1 Adjusted healthcare resource utilisation by ACT score in patients with asthma for the number of (a) healthcare professional visits, (b) emergency department visits, (c) hospitalisations ${ }^{*} p \leq 0.001$; $p$-values represent significance of the regression coefficient in the regression model with patients with well-controlled asthma (ACT score 20-25) as the reference group. Covariates included age, sex, Charlson Comorbidity Index, race/ethnicity, income, body mass index, smoking status, exercise, insurance type and years diagnosed with asthma. ACT, asthma control test; ED, emergency department; HCP, healthcare professional.

all groups (ACT: 20-25 vs 16-19 and $\leq 15$ ) reported using rescue medication $(75.8 \%$ vs $80.8 \%$ and $80.4 \%)$.

\section{ADHERENCE TO ASTHMA MEDICATION}

There were significant differences in adherence to asthma medication by ACT groups with a greater proportion of patients with well-controlled asthma reporting 'high adherence' relative to those with partly controlled or poorly controlled asthma (23.3\% vs $19.9 \%$ and $19.4 \%$; $\mathrm{p}<0.001$ for ACT: $20-25$ vs $16-19$ and $\leq 15)$. Adherence was not controlled for in the multivariable analysis.

\section{Healthcare resource use and adjusted estimated annual direct cost per person}

After adjusting for covariates, well-controlled asthma (ACT score 20-25) compared with partly controlled (ACT score 16-19) or poorly controlled asthma (ACT score $\leq 15$ ) was associated with significantly fewer $(\mathrm{p}<0.001)$ healthcare provider visits, ED visits and hospitalisations in the previous 6 months (figure 1). Adjusted mean direct costs (derived from patients' HRU) were significantly lower for patients with well-controlled asthma (\$6012) compared with patients with partly controlled (\$8554; RR 1.42) or poorly controlled asthma ( $\$ 15262$; RR 2.54) $(\mathrm{p}<0.001$; figure 2).

\section{Work impairment and adjusted estimated annual indirect cost} per person

After adjusting for covariates, well-controlled asthma compared with partly controlled or poorly controlled asthma was associated with significantly lower $(p<0.001)$ mean percentages of work absenteeism, work presenteeism, overall work impairment and activity impairment (figure 3). Adjusted mean indirect costs (derived from patients' work productivity loss) were significantly

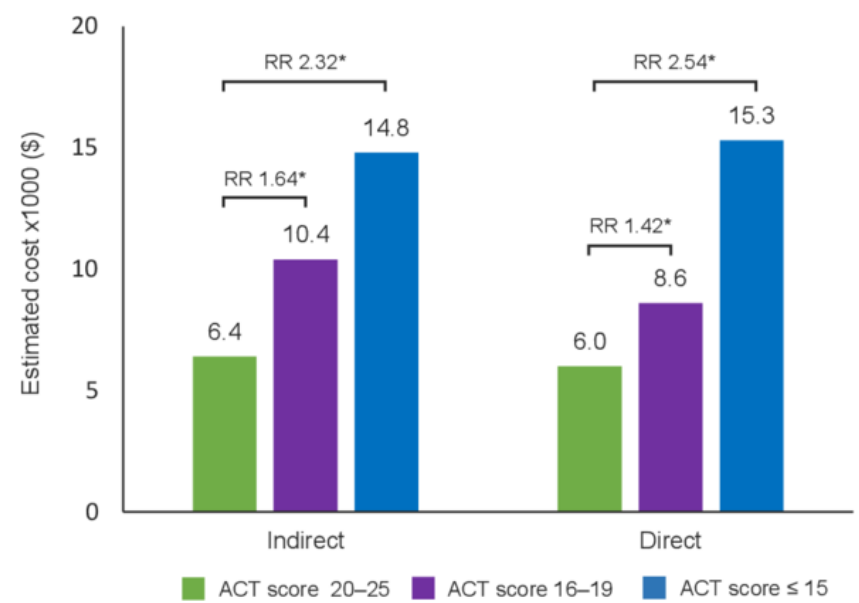

Figure 2 Adjusted mean annual costs per person by ACT score in patients with asthma * $p \leq 0.001$; $p$-values represent significance of the regression coefficient in the regression model with patients with well-controlled asthma (ACT score 20-25) as the reference group. Indirect costs were derived from patient's work productivity with the use of WPAI-GH v2.0; direct costs were derived from patient's healthcare resource use in the previous 6 months. Covariates included age, sex, Charlson Comorbidity Index, race/ethnicity, income, body mass index, smoking status, exercise, insurance type and years diagnosed with asthma. $\mathrm{ACT}$, asthma control test; RR, rate ratio; WPAI-GH, Work Productivity and Activity Impairment-General Health Scale.

lower for patients with well-controlled asthma (\$6353) compared with patients with partly controlled (\$10 448; RR 1.64) or poorly controlled asthma (\$14 764; RR 2.32) $(\mathrm{p}<0.001)$.

\section{Impact of ACT score on HRQoL}

After adjusting for covariates, patients with wellcontrolled asthma had statistically significantly higher adjusted mean EQ-5D-5L index and SF-6D Health Utilities Index scores than patients with partly controlled or poorly controlled asthma $(\mathrm{p}<0.001)$ (figure 4$)$. For the EQ-5D-5L index, the difference in score between wellcontrolled and poorly controlled asthma patients was 0.1 , thereby exceeding the EQ-5D-5L index MID of $0.07 .^{922} 23$

For the SF-6D Health Utilities Index, the differences in scores between patients with well-controlled and partly controlled or poorly controlled asthma were 0.05 and 0.09 , respectively, thus exceeding the SF-6D Health Utilities Index MID of $0.041 .^{22}$ In addition, the overall MCS score and PCS score of the SF-36V.2 were significantly higher in patients with well-controlled asthma, versus patients with partly controlled or poorly controlled asthma $(p<0.001)$ (online supplementary table S1). Significant differences between patients grouped by their ACT score were also observed for each of the eight domains in the SF-36V.2 (all $\mathrm{p}<0.001$ ) (online supplementary table $\mathrm{S} 1$ ). The difference in scores between patients with well-controlled and partly controlled or poorly controlled asthma exceeded the MID of $3^{21}$ for both SF-36V.2 MCS and PCS (figure 1). 


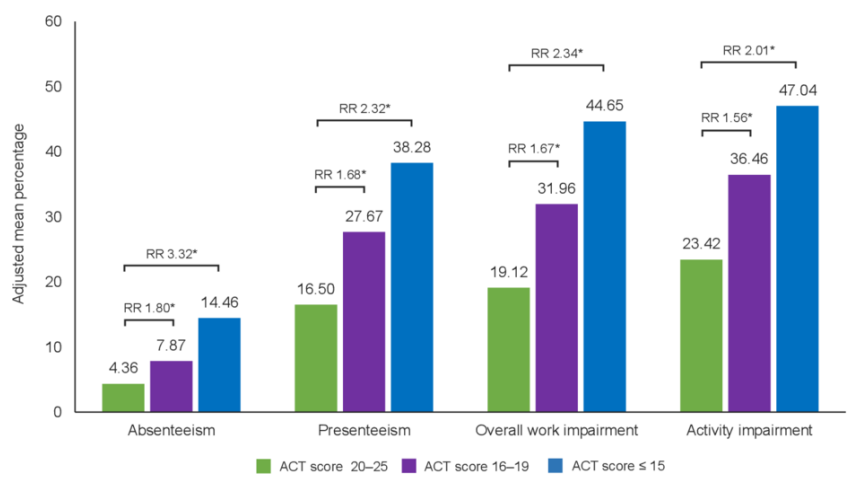

Figure 3 Adjusted mean work productivity by ACT score in patients with asthma * $\mathrm{p} \leq 0.001 ; \mathrm{p}$-values represent significance of the regression coefficient in the regression model with patients with well-controlled asthma (ACT score 20-25) as the reference group. Covariates included age, sex, Charlson Comorbidity Index, race/ethnicity, income, body mass index, smoking status, exercise, insurance type and years diagnosed with asthma. ACT, asthma control test; $\mathrm{RR}$, rate ratio.

\section{DISCUSSION}

The current study using US NHWS data from a large cross-section of patients with a self-reported physician diagnosis of asthma showed that lower levels of asthma control, as measured by ACT scores, were associated

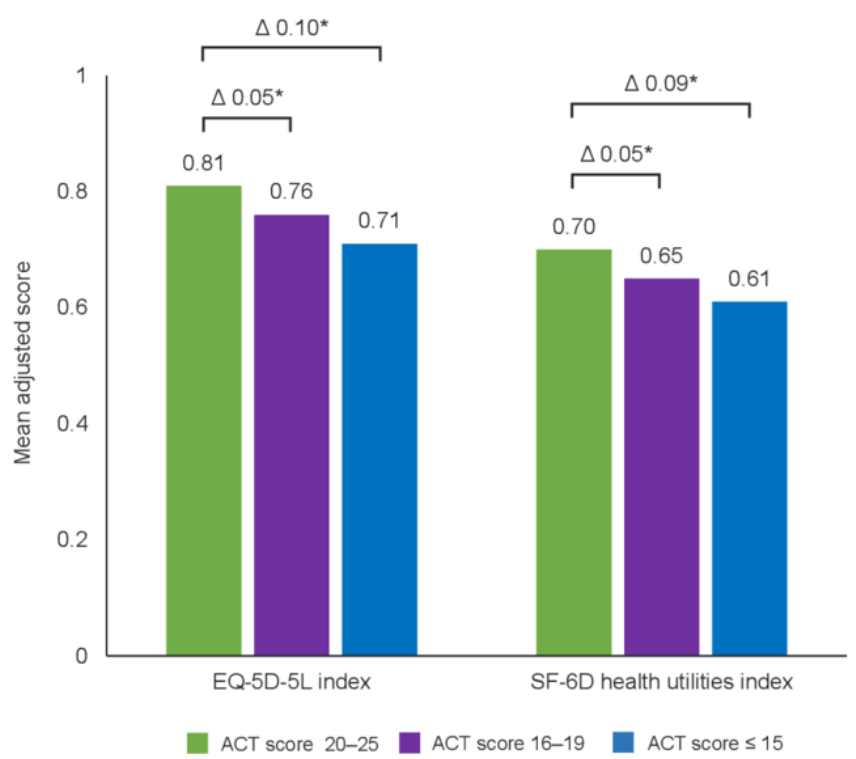

Figure 4 Mean adjusted EQ-5D-5L and SF-6D Health Utilities Index scores by ACT score in patients with asthma. ${ }^{*} \mathrm{p} \leq 0.001 ; \mathrm{p}$-values represent significance of the regression coefficient in the regression model with patients with well-controlled asthma (ACT score 20-25) as the reference group. Covariates included age, sex, Charlson Comorbidity Index, race/ethnicity, income, body mass index, smoking status, exercise, insurance type and years diagnosed with asthma. EQ-5D-5L MID=0.07; SF-6D Health Utilities Index MID=0.041. ACT, asthma control test; EQ5D-5L, EuroQoL-5 Dimensions-5 Levels; MID, minimally important difference; RR, rate ratio; SF-6D, Short-Form SixDimension. with greater economic burden and lower HRQoL. Partly controlled or poorly controlled asthma was associated with greater HRU, resulting in higher direct costs and lower work productivity, leading to higher indirect costs, compared with patients with well-controlled asthma. Incremental improvements in ACT scores were shown to have the potential to improve patients' HRQoL with clinically meaningful differences (MID thresholds) as measured by well-recognised and validated QoL instruments: EQ-5D-5L, ${ }^{22}{ }^{23}$ SF-36V..2 ${ }^{22}$ and including both SF-36V.2 MCS and PCS scores. ${ }^{21}$

These findings are corroborated by prior analyses of NHWS data from Europe ${ }^{12} 13$ and the USA (using data collected between 2011 and 2013). ${ }^{11}$ In the current analyses, however, a smaller proportion of patients were characterised with partly controlled and poorly controlled asthma (ACT score <20;38\%) compared with $56 \%{ }^{13}$ $64 \%^{12}$ and $54 \%^{11}$ of patients from the German, UK and US NHWS, respectively. This, in part, reflects differences in the selection of patients for each study-with the current survey including all patients with self-reported physician diagnosis of asthma (but not COPD) and receiving a broad range of therapies-whereas earlier published reports analysed a subgroup of patients on maintenance treatment with ICS plus LABA (so the impact of maintenance therapy on asthma control could be identified). It is notable that in the current analyses, more than $60 \%$ of patients with self-reported asthma indicated that they were not being treated with ICS and/or LABA; however, more than three-quarters of respondents to the survey reported using rescue medication within the past 4 weeks. In patients with good asthma control, there was a greater preponderance of patients who had changed their existing asthma medication in the last year $(74.3 \%$ vs $66.3 \%$ and $57.5 \%$ of patients with wellcontrolled asthma, vs patients with partly controlled or poorly controlled asthma, respectively), suggesting that active asthma management was more common in patients with good asthma control. In terms of risk factors for poor control, a higher proportion of poorly controlled and partly controlled asthma patients compared with well-controlled asthma patients were non-white, had less than a 4-year college degree, had lower income, did not have private insurance, did not exercise, were obese and were current smokers. A greater proportion of patients with poorly controlled asthma had a higher comorbidity burden (ie, higher CCI) than patients with partly controlled or well-controlled asthma, and poorly controlled and partly controlled patients also reported higher levels of severe persistent asthma (when not using asthma medication) than well-controlled patients. After adjusting for patient differences, a higher ACT score was associated with less HRU, less work productivity loss and associated costs and better HRQoL. These findings remained even after controlling for covariates.

Our findings of the negative impact of poorly controlled asthma on health and economic outcomes support those observed in previous studies. A cross-sectional analysis 
of patients with asthma from the 2006 US NHWS was previously performed. ${ }^{24}$ After adjusting for confounders, patients with an ACT score $\geq 20$ reported higher physical and mental HRQoL scores (SF-8); fewer ED visits, hospitalisation days and medical provider visits; and lower levels of overall work productivity loss. Among patients included in the Asthma Insights and Reality in Asia-Pacific survey, 59\% had an ACT score $<20 .{ }^{25}$ Among these patients, $52 \%$ reported at least one unscheduled healthcare visit related to asthma, including in-patient care, an ED visit, or an unscheduled primary care visit, in the previous year. Overall, poorer asthma control was associated with an increased frequency of unscheduled healthcare resource use and elevated cost, and these findings were consistent across a range of Asian Pacific areas. In another example, the telephone survey-based Asthma Insights and Reality in Europe study found that $48 \%$ of patients had an ACT score $<20 .{ }^{26}$ Patients with an ACT score $<20$ had greater use of unscheduled healthcare resources and costs than those with an ACT score of $\geq 20$; indeed, mean per-patient annual cost of asthma management for patients with an ACT score $<15$ was $€ 1604$, compared with $€ 512$ for those with an ACT score of $15-19$ and $€ 232$ with a score of $\geq 20$.

It is important to consider the results in the context of strengths and limitations of the study design. The analyses were based on 2 years of data from the US NHWS in order to identify a large representative sample of patients with accompanying patient-reported HRQoL data (from well-recognised and validated instruments) and comprehensive data on HRU and the impact of asthma on work productivity. A much broader spectrum of patients with self-reported asthma were included in these analyses than in other similar contemporary studies, and adjustments were made for the variance between groups using a range of covariates (including age, sex, race, education, income, insurance type, BMI, smoking status, exercise, years diagnosed with asthma and as well as comorbidities (CCI) ) in order to provide a more accurate estimate of the relationship between asthma control and patientreported outcomes.

As with other similar studies, there are inherent limitations to online, survey-based studies; for example, a diagnosis of asthma by a physician could not be corroborated beyond what was reported by the patients. In addition, the answers to survey questions were based on patient perception at just one point in time. Given that the data were self-reported, they may be subject to recall errors, and the responses to questions were not confirmed using patient health records. Although recruitment to the NHWS is designed to be representative of the US adult population, there is likely to be bias in the selection of patients because of the nature of online surveys. These tend to under-represent elderly (and non-computer literate) patients and patients with more severe asthma, and over-represent those with a greater motivation and ability to participate. If the study represents patients with less severe asthma, then the true burden of asthma and lack of asthma control is greater than what is reported in the current study. Finally, these analyses were crosssectional, rather than longitudinal, therefore it is not possible to draw causal inferences between predictors and outcomes. While it is possible for adherence to be a covariate that influences the relationship between asthma controls and outcomes such as HRQoL, WPAI, HRU and costs, when the regressions were reran with adherence as a covariate, it was found that this did not change the significance or direction of the findings.

Longitudinal data using a large sample of patients may help us to better understand possible associations between changes in asthma control and health and economic outcomes. Moreover, by using predictive models, it may be possible to identify patient types who are at risk of maintaining poor control or at risk of worsening control. Subsequent interventions could then aim to improve the ACT score for these patients.

Despite these limitations, the study provides a contemporary picture of HRQoL and HRU across the spectrum of patients with asthma. The analyses also reinforce the findings from other studies showing that the ACT, due to its ease of use by patients, is a useful tool, which can detect meaningful differences in asthma control in the population-based on patients' recall of asthma symptoms, rescue medication, effect of asthma on daily functioning and patient's perception of asthma control over the previous 4 weeks. ${ }^{27}$ Relative to patients with less wellcontrolled asthma, good asthma control was associated with improved HRQoL and reduced costs.

In conclusion, this large US study demonstrates that poorly controlled asthma has a negative impact on patient HRQoL and direct and indirect healthcare costs. Our findings from a contemporary US asthma population support those from previous studies among asthma populations. Therefore, interventions to improve asthma control may result in direct and indirect annualised cost savings as well as improved HRQoL.

Acknowledgements Medical writing support was provided by Melanie Francis, of Zoetic Science (an Ashfield company, part of UDG Healthcare plc), and was funded by Teva Branded Pharmaceutical Products R\&D Inc.

Contributors All authors had full access to all the data in the study and had final responsibility for the decision.

Funding Funding was provided by Teva Branded Pharmaceutical Products R\&D. Teva employees were involved in the study design, data collection and analysis, and in the writing of this manuscript. All authors had full access to all the data in the study and had final responsibility for the decision to submit for publication.

Competing interests LKL is an employee of Kantar, Health Division, which received funding from Teva Pharmaceuticals for the purposes of this study. KR is a former employee of Teva Pharmaceuticals. GS and RA are employees of Teva Pharmaceuticals. MS has received research support from ALK, GSK, Medlmmune and Merck \& Co Inc.

Patient consent for publication Not required.

Provenance and peer review Not commissioned; externally peer reviewed.

Data availability statement Data are available upon reasonable request. Qualified researchers may request access to patient level data and related study documents including the study protocol and the statistical analysis plan. Requests will be reviewed for scientific merit, product approval status and conflicts of interest. Patient level data will be deidentified and study documents will be redacted to protect the privacy of trial participants and to protect commercially confidential 
information. Please email USMedlnfo@tevapharm.com to make your request.

Open access This is an open access article distributed in accordance with the Creative Commons Attribution Non Commercial (CC BY-NC 4.0) license, which permits others to distribute, remix, adapt, build upon this work non-commercially, and license their derivative works on different terms, provided the original work is properly cited, appropriate credit is given, any changes made indicated, and the use is non-commercial. See: http://creativecommons.org/licenses/by-nc/4.0/.

\section{REFERENCES}

1 Enilari O, Sinha S. The global impact of asthma in adult populations. Ann Glob Health 2019;85:85.

2 Centers for Disease Control and Prevention (CDC). Most recent asthma data. Available: https://www.cdc.gov/asthma/most recent data.htm [Accessed Jan 2020].

3 Nurmagambetov T, Kuwahara R, Garbe P. The economic burden of asthma in the United States, 2008-2013. Ann Am Thorac Soc 2018;15:348-56.

4 Global Initiative for Asthma. Global strategy for asthma management and prevention 2018.

5 Rabe KF, Vermeire PA, Soriano JB, et al. Clinical management of asthma in 1999: the asthma insights and reality in Europe (AIRE) study. Eur Respir J 2000;16:802-7.

6 Rabe KF, Adachi M, Lai CKW, et al. Worldwide severity and contro of asthma in children and adults: the global asthma insights and reality surveys. J Allergy Clin Immunol 2004;114:40-7.

7 Soriano JB, Rabe KF, Vermeire PA, et al. Predictors of poor asthma control in European adults. J Asthma 2003;40:803-13.

8 Nunes C, Pereira AM, Morais-Almeida M. Asthma costs and social impact. Asthma Res Pract 2017:3:1.

9 Lingner H, Ernst S, Großhennig A, et al. Asthma control and health-related quality of life one year after inpatient pulmonary rehabilitation: the ProKAR study. J Asthma 2015;52:614-21.

10 Schatz M, Sorkness CA, Li JT, et al. Asthma control test: reliability, validity, and responsiveness in patients not previously followed by asthma specialists. J Allergy Clin Immunol 2006;117:549-56.

11 Lee LK, Obi E, Paknis B, et al. Asthma control and disease burden in patients with asthma and allergic comorbidities. J Asthma 2018;55:208-19.

12 Pavord ID, Mathieson N, Scowcroft A, et al. The impact of poor asthma control among asthma patients treated with inhaled corticosteroids plus long-acting $\beta 2$-agonists in the United Kingdom: a cross-sectional analysis. NPJ Prim Care Respir Med 2017;27:17.
13 Kondla A, Glaab T, Pedersini R, et al. Asthma control in patients treated with inhaled corticosteroids and long-acting beta agonists: a population-based analysis in Germany. Respir Med 2016;118:58-64.

14 National Health and Wellness Survey. Patient-Reported healthcare insights. Kantar health, 2016. Available: http://www.kantarhealth. com [Accessed Jan 2020].

15 Charlson ME, Pompei P, Ales KL, et al. A new method of classifying prognostic comorbidity in longitudinal studies: development and validation. J Chronic Dis 1987;40:373-83.

16 Morisky DE, Ang A, Krousel-Wood M, et al. Predictive validity of a medication adherence measure for hypertension control. J Clin Hypertens 2008;10:348-54.

17 Agency for Healthcare Research and Quality. Medical expenditure panel survey, 2014. Available: https://meps.ahrq.gov/mepsweb/ survey_comp/survey.jsp\#Questionnaires [Accessed Jan 2020].

18 Reilly MC, Zbrozek AS, Dukes EM. The validity and reproducibility of a work productivity and activity impairment instrument. Pharmacoeconomics 1993:4:353-65.

19 Work Productivity and Activity Impairment Questionnaire: Genera Health V2.0 (WPAl:GH). Reilly Associates, 2010. Available: http:// www.reillyassociates.net/WPAI_GH.html [Accessed Jan 2020].

20 Herdman M, Gudex C, Lloyd A, et al. Development and preliminary testing of the new five-level version of EQ-5D (EQ-5D-5L). Qual Life Res 2011;20:1727-36.

21 Ware JE, Kosinski M, Gandek B. Sf-36 health survey: manual and interpretation guide. Quality Metric Incorporated: Lincoln, RI, 2000.

22 Walters SJ, Brazier JE. Comparison of the minimally important difference for two health state utility measures: EQ-5D and SF-6D. Qual Life Res 2005;14:1523-32.

23 McClure NS, Sayah FA, Xie F, et al. Instrument-defined estimates of the minimally important difference for EQ-5D-5L index scores. Value Health 2017;20:644-50.

24 Williams SA, Wagner S, Kannan $\mathrm{H}$, et al. The association between asthma control and health care utilization, work productivity loss and health-related quality of life. J Occup Environ Med 2009;51:780-5.

25 CKW Let al. Asthma control and its direct healthcare costs: findings using a derived Asthma Control Test ${ }^{\mathrm{TM}}$ score in eight Asia-Pacific areas. European Respiratory Review 2006;15:24-9.

26 Vervloet $\mathrm{D}$, Williams AE, Lloyd A, et al. Costs of managing asthma as defined by a derived Asthma Control Test ${ }^{\mathrm{TM}}$ score in seven European countries. European Respiratory Review 2006;15:17-23.

27 Athanazio R, Carvalho-Pinto R, Fernandes FLA, et al. Can severe asthmatic patients achieve asthma control? A systematic approach in patients with difficult to control asthma followed in a specialized clinic. BMC Pulm Med 2016;16:153. 